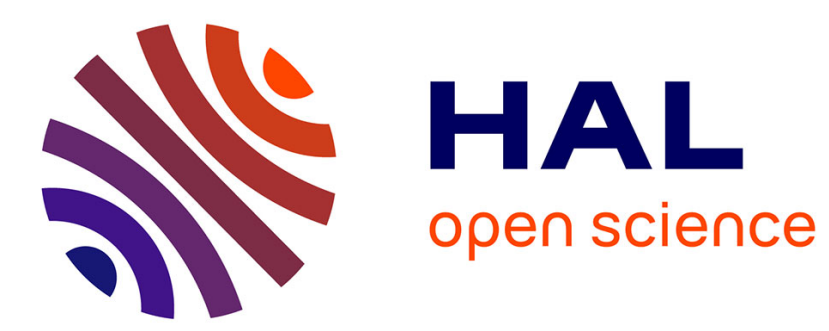

\title{
HIGH TEMPERATURE LATTICE PARAMETERS OF ZnSiP2, ZnGeP2 AND CdGeP2
}

A. J. Miller, R. Humphreys, B. Chapman

\section{To cite this version:}

A. J. Miller, R. Humphreys, B. Chapman. HIGH TEMPERATURE LATTICE PARAMETERS OF ZnSiP2, ZnGeP2 AND CdGeP2. Journal de Physique Colloques, 1975, 36 (C3), pp.C3-31-C3-34. 10.1051/jphyscol:1975306 . jpa-00216276

\section{HAL Id: jpa-00216276 https://hal.science/jpa-00216276}

Submitted on 1 Jan 1975

HAL is a multi-disciplinary open access archive for the deposit and dissemination of scientific research documents, whether they are published or not. The documents may come from teaching and research institutions in France or abroad, or from public or private research centers.
L'archive ouverte pluridisciplinaire HAL, est destinée au dépôt et à la diffusion de documents scientifiques de niveau recherche, publiés ou non, émanant des établissements d'enseignement et de recherche français ou étrangers, des laboratoires publics ou privés. 


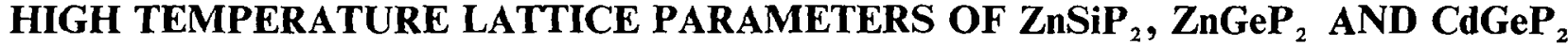

\author{
A. MILLER $\left({ }^{*}\right)$, R. G. HUMPHREYS and B. CHAPMAN
}

School of Physics, University of Bath, U. K.

\begin{abstract}
Résumé. - Nous avons étudié la variation des paramètres cristallins des semiconducteurs à structure chalcopyrite, $\mathrm{ZnSiP}_{2}, \mathrm{ZnGeP}_{2}$ et $\mathrm{CdGeP}_{2}$ entre la température ambiante et $1100^{\circ} \mathrm{C}$ en utilisant un appareil de diffraction $\mathrm{X}$ à haute température. Pour les trois composés, la compression tétragonale croît avec la température. Nous avons interprété ces résultats en termes de dilatation des liaisons II-V et IV-V.

Abstract. - The variation of the lattice parameters from room temperature to $1.100{ }^{\circ} \mathrm{C}$ have been studied for the chalcopyrite semiconductors, $\mathrm{ZnSiP}_{2}, \mathrm{ZnGeP}_{2}$ and $\mathrm{CdGeP}_{2}$ using a high temperature X-ray camera. All three compounds show an increase in the tetragonal compression with temperature. The results are interpreted in terms of the thermal expansions of the II-V and IV-V bonds.
\end{abstract}

1. Introduction. - The variation of the lattice parameters of three $A^{1 \mathrm{II}} B^{\mathrm{IV}} C_{2}^{\mathrm{V}}$ chalcopyrite compounds, $\mathrm{ZnSiP}_{2}, \mathrm{ZnGeP}_{2}$ and $\mathrm{CdGeP}_{2}$ have been measured by the high temperature $\mathrm{X}$-ray technique. The range covered was from room temperature to the decomposition temperature for each material. There were three reasons for carrying out this study.

Firstly, as some of these materials are potentially useful for use in heterojunctions with binary semiconductors, the lattice parameters at the temperature of growth should be known for liquid or vapour epitaxy [1]. Secondly, some of the compounds have been reported to have high temperature structural modifications which have not been identified directly. In particular, differential thermal analysis indicates a phase transition at $950^{\circ} \mathrm{C}$ in $\mathrm{ZnGeP}_{2}$, but the high temperature structure has not been retained by quenching to room temperature [2, 3, 4]. Finally, it is interesting to observe how the tetragonal compression, or c/a ratio varies with temperature and to consider this in terms of the two types of bond of the chalcopyrite structure.

\section{TABLE}

Room temperature lattice parameters

$$
\begin{array}{ccc}
\mathrm{ZnSiP}_{2} & \text { (Zn solution) } & \\
\multicolumn{1}{c}{a=5.399 \quad c=10.438} & c / a=1.933 \\
\mathrm{ZnGeP}_{2} & \text { (Pb solution) } & \\
\quad a=5.464 \quad c=10.708 & c / a=1.960 \\
\mathrm{CdGeP}_{2} & \text { (Pb solution) } & \\
\quad a=5.741 \quad c=10.770 & c / a=1.876
\end{array}
$$

(*) Present address : Department of Physics, Heriot-Watt University, Edinburgh, U. K.
Some work has previously been carried out on thermal expansions of these compounds. $\mathrm{CdGeAs}_{2}$ has been studied by X-ray [5] and optomechanical [6] techniques. There is also a Russian report of high temperature $\mathrm{X}$-ray measurements of several II-IV-V compounds including the three compounds of type $\mathrm{ZnSnC}_{2}$ which have zero tetragonal compression at room temperature [7].

2. Experimental. - Single crystals were grown from molten metal solution; $\mathrm{ZnSiP}_{2}$ in zinc [8] and $\mathrm{ZnGeP}_{2}$ and $\mathrm{CdGeP}_{2}$ in lead [9]. Powdered samples were sealed in $0.3 \mathrm{~mm}$ diameter silica tubes and mounted on a $19 \mathrm{~cm}$ Unicam S150 high temperature camera with Van Arkel film configuration. The camera was previously calibrated using alumina $\left(\mathrm{Al}_{2} \mathrm{O}_{3}\right)$. Heating was by radiation from electrical elements surrounding the sample in an evacuated cavity. A least squares fit of the data to a correction function took account of absorption and eccentricity errors by extrapolating the results to $180^{\circ}$ scattering.

3. Results and discussion. - Figure 1 shows the results obtained for the variations of $a, c, c / a$ and the volume $V$ with temperature for the three compounds. The first point to note is that $\mathrm{ZnGeP}_{2}$ remained in the chalcopyrite structure until it decomposed above $1.020^{\circ} \mathrm{C}$. The melting point of $\mathrm{ZnGeP}_{2}$ is $1.025^{\circ} \mathrm{C}$ [2], so that no high temperature zinc blende phase appears to exist for this material, contrary to expectation from differential thermal analysis data. The results for $\mathrm{ZnSiP}_{2}$ (m. p. $1.370^{\circ} \mathrm{C}$ ) [10] were limited to below $1.100^{\circ} \mathrm{C}$, due to softening of the silica container. The highest temperature obtained for $\mathrm{CdGeP}_{2}$ (m) p. $800^{\circ} \mathrm{C}$ ) [10] was $755^{\circ} \mathrm{C}$ after which it decomposed. Again, no high temperature phases were observed up to these temperatures. 

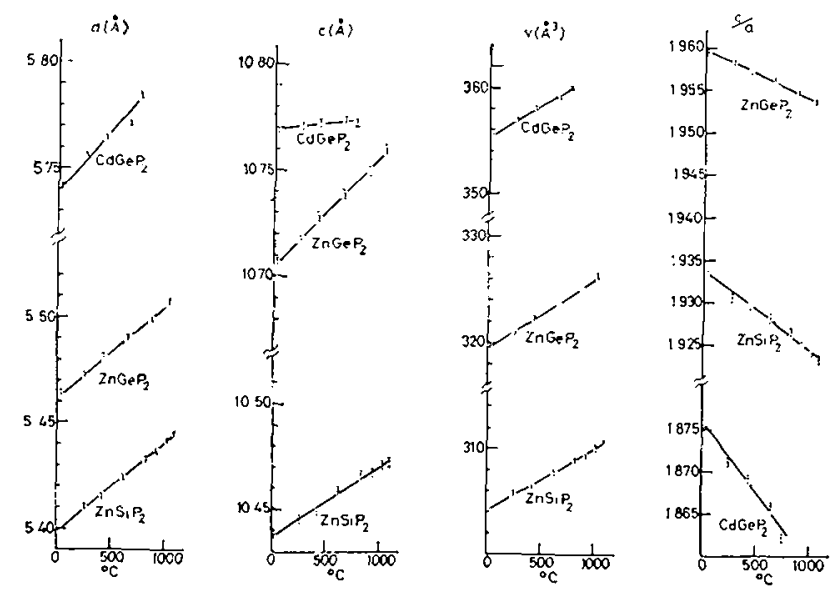

FIG. 1. - Lattice parameters of $\mathrm{ZnSiP}_{2}, \mathrm{ZnGeP}_{2}$ and $\mathrm{CdGeP}_{2}$ between $0^{\circ}$ and $1.000{ }^{\circ} \mathrm{C}$.

The second point of interest is the result that the $c / a$ axial ratios are seen to decrease with increasing temperature. This is away from the ideal value of 2 . This seems surprising at first sight because one would normally expect a move towards the more symmetrical pseudocubic position with $c / a=2$ at higher temperature. It is also evident from these three compounds that the rate of change of distortion increases with tetragonal compression as pointed out by Weaire et al. [11]. This also applies to the $\mathrm{CdGeAs}_{2}$ results $[5,6]$ and for the results of the three zinc-tin compounds containing phosphorus, arsenic and antimony which have zero tetragonal compression at room temperature since no shift from $c / a=2$ was observed on heating to $600^{\circ} \mathrm{C}[7]$.

Our results showed linear increases of lattice parameters with temperature within experimental error. In table II, we quote the thermal expansion coefficients given by the best straight line fits to the data. These are thus average coefficients for the temperature ranges covered and are normalised by dividing by the room temperature values.

We note that although the coefficients for $a, c$ and $c / a$ vary significantly for the materials studied, they have very similar volume coefficients. The values for
$\mathrm{GaP}$ [12], the isoelectronic analogue of $\mathrm{ZnGeP}_{2}$ are listed for comparison and are seen to be significantly smaller. The free $x$-parameter of the chalcopyrite structure complicates direct comparison, but this may be due to a larger average ionicity of the ternary compounds. This will be considered later.

We have attempted to interpret the increase in tetragonal compression with temperature in terms of the thermal expansions of the individual $I I-V$ and IV-V bonds, by applying the Abrahams and Bernstein relations [13] to our results. Work by these investigators produced the presently accepted picture of the $A^{\mathrm{II}} B^{\mathrm{IV}} C_{2}^{\mathrm{V}}$ compounds as consisting of an almost perfect $B C_{4}$ tetrahedral arrangement with tetrahedral angles within $1 \%$ of the ideal value of $109.47^{\circ}$. The IV-V bonds thus show strong directional covalent character while the distortion is taken up in the position of the group II cations. The net result is a relative displacement of the anions (P) towards the two nearest neighbour group IV cations, figure 2 . This shift determines the $x$-parameter of the chalcopyrite structure. Assuming a perfect tetrahedron, the $x$ parameter and the bond lengths can be expressed in terms of the lattice parameters, $a$ and $c$,

$$
\begin{aligned}
x & =0.5-\left[\frac{c^{2}}{32 \cdot a^{2}}-\frac{1}{16}\right]^{1 / 2} \\
A-C & =\left[a^{2} \cdot x^{2}+\frac{4 a^{2}+c^{2}}{64}\right]^{1 / 2} \\
B-C & =\left[a^{2}\left(\frac{1}{2}-x\right)^{2}+\frac{4 a^{2}+c^{2}}{64}\right]^{1 / 2} \\
c & =\frac{8}{\sqrt{3}}(B-C) .
\end{aligned}
$$

Lind and Grant [14] showed that, except for the compounds of type $\mathrm{ZnSnC}_{2}, A^{\mathrm{II}} B^{\mathrm{IV}} C_{2}^{\mathrm{V}}$ compounds fell close to the line defined by eq. (4). Figure 3 shows the calculated $x$ parameters for the present results and also the previously measured room temperature values [13, $14,15]$. The $x$ parameters all increase with temperature as expected for increasing distortion from the cubic value of 0.25 , so the phosphorus atoms move relati-

TABLE II

Average thermal expansion coefficients

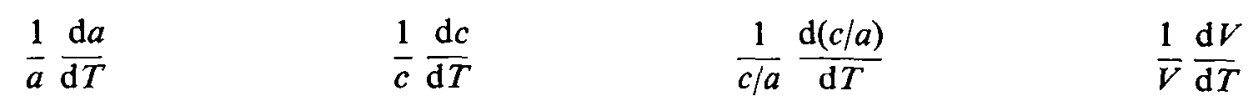

\begin{tabular}{lllll}
$\mathrm{ZnSiP}_{2}$ & $7.9 \times 10^{-6}$ & $3.2 \times 10^{-6}$ & $-4.8 \times 10^{-6}$ & $1.9 \times 10^{-5}$ \\
$\mathrm{ZnGeP}_{2}$ & $7.8 \times 10^{-6}$ & $5.0 \times 10^{-6}$ & $-2.9 \times 10^{-6}$ & $2.0 \times 10^{-5}$ \\
\hline $\mathrm{CdGeP}_{2}$ & $8.9 \times 10^{-6}$ & $3.7 \times 10^{-7}$ & $-9.3 \times 10^{-6}$ & $1.8 \times 10^{-5}$ \\
$\overline{\mathrm{GaP}}$ & $4.65 \times 10^{-6}$ & & & $1.40 \times 10^{-5}$
\end{tabular}

Thermal expansion coefficients are defined by, $\alpha=\frac{1}{\xi_{0}} \cdot \frac{\mathrm{d} \xi}{\mathrm{d} T}$ where $\xi_{0}$ is the room temperature value. 


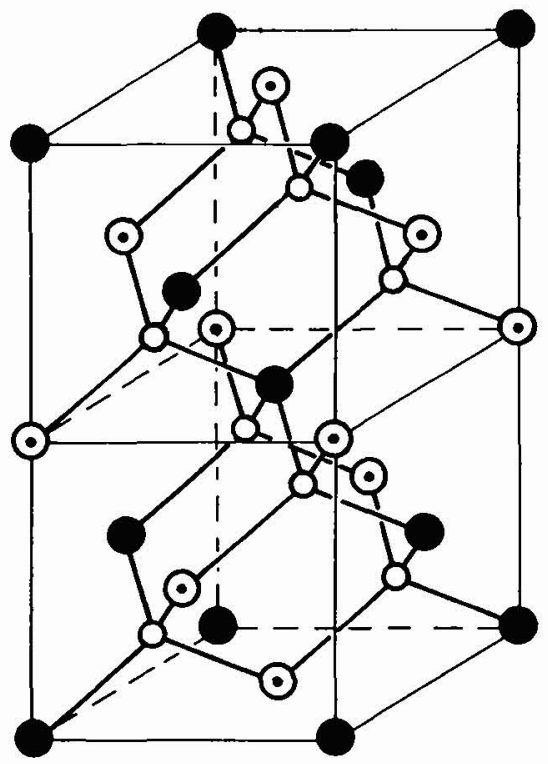

OZn $\odot \mathrm{Ge}$ OP

FIG. 2. - Chalcopyrite structure.

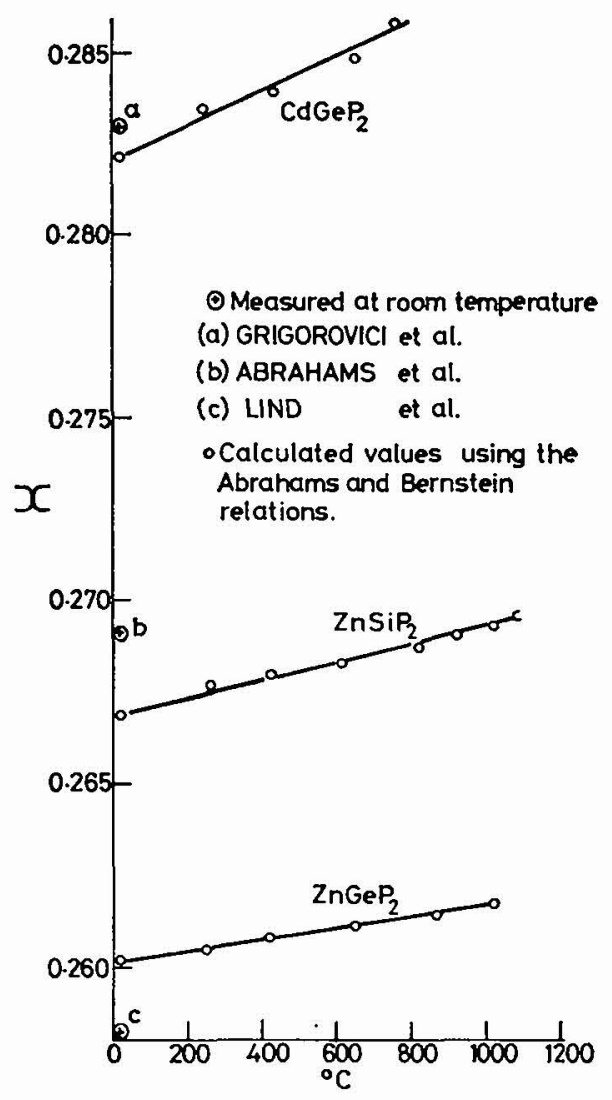

Fig. 3. - Calculated $x$ parameters. vely closer to the group IV atoms. The thermal expansions of the bonds given by eq. (2) and (3) are shown in figure 4 and indicate the reason for the increase in tetragonal distortion with temperature. The more ionic II-V bonds have higher thermal expansion coefficients than the covalent IV-V bonds, so that, the group $\mathrm{V}$ atoms move relatively nearer the group IV cations on heating, thus increasing the distortion through eq. (1). The calculated thermal expansions are listed in table III along with existing values for other materials [12, 16, 17]. Unfortunately data do not exist for all of the binary analogues of these compounds. Covalent silicon and germanium have small expansion coefficients. The value for the slightly ionic gallium phosphide is larger. These may be compared with the Si-P and Ge-P coefficients although the value obtained

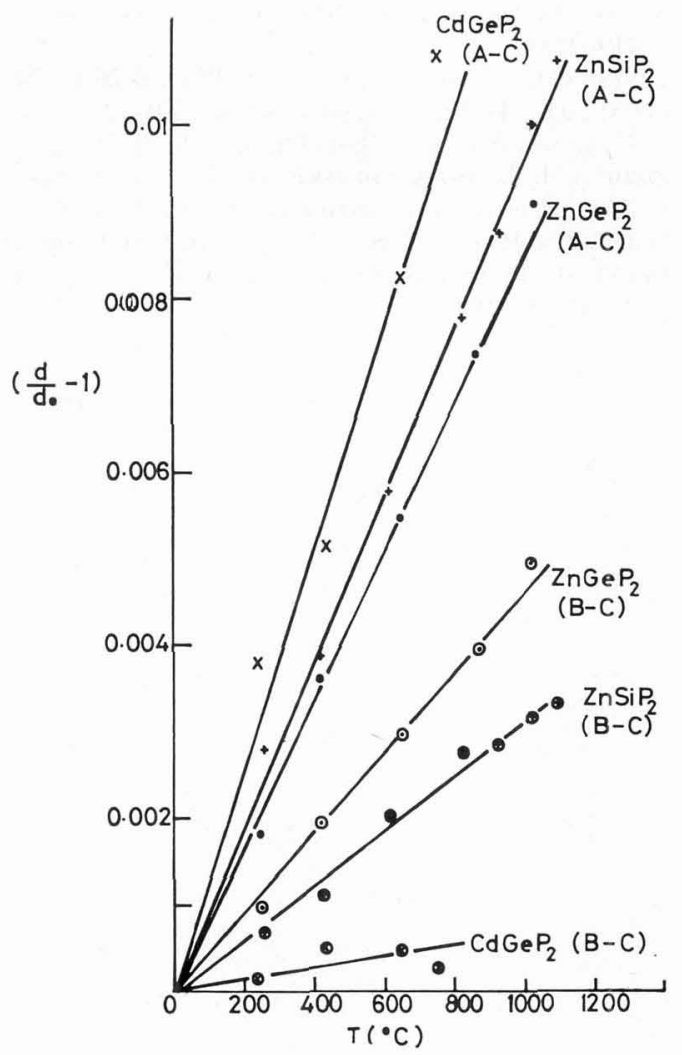

Fig. 4. - Calculated thermal expansions of the $A-C$ and $B-C$ bonds.

TABLE III

Calculated bond expansion coefficients

$\begin{array}{lccc} & \frac{1}{x} \frac{\mathrm{d} x}{\mathrm{~d} T} & \frac{1}{A-C} \frac{\mathrm{d}(A-C)}{\mathrm{d}} \frac{1}{B-C} \frac{\mathrm{d}(B-C)}{\mathrm{d} T} \\ \mathrm{ZnSiP}_{2} & 9.2 \times 10^{-6} & 9.8 \times 10^{-6} & 2.8 \times 10^{-6} \\ \mathrm{ZnGeP}_{2} & 5.8 \times 10^{-6} & 9.1 \times 10^{-6} & 5.0 \times 10^{-6} \\ \mathrm{CdGeP} & 1.7 \times 10^{-5} & 1.5 \times 10^{-5} & 6.4 \times 10^{-7} \\ \mathrm{Si} & 1.5 & 2.95 \times 10^{-6} & \\ \mathrm{Ge} & & 3.01 \times 10^{-6} & \\ \mathrm{GaP} & & 4.65 \times 10^{-6} & \\ \mathrm{ZnSe} & & 8.01 \times 10^{-6} & \end{array}$


from this model for $\mathrm{CdGeP}_{2}$ looks anomalously low. The $\mathrm{Zn}-\mathrm{P}$ and $\mathrm{Cd}-\mathrm{P}$ coefficients resemble the more ionic $\mathrm{ZnSe}$ value.

To conclude, no high temperature structural modification has been found for $\mathrm{ZnGeP}_{2}$ and the observed increase in tetragonal distortions of $\mathrm{ZnSiP}_{2}, \mathrm{ZnGeP}_{2}$ and $\mathrm{CdGeP}_{2}$ with temperature can be interpreted in terms of the larger thermal expansion coefficients of the more ionic II-V bonds. Bulk expansion coefficients are larger than group IV and III-V analogues.

Acknowledgments. - The Science Research Council and Honeywell Inc. are acknowledged for financial assistance.

\section{References}

[1] Shay, J. L., Bachmañ, K., Buehler, E., Wernick, J. H. Appl. Phys. Lett. 5 (1973) 226.

[2] BUeHLER, E., Wernick, J. H., Wiley, J. D., J. Electron. Mater. 2 (1973) 445.

[3] Masumoto, K., Isomura, S., Goto, W., J. Phys. Chem. Solids 27 (1966) 1939.

[4] Ray, B., Payne, A. J., Burrell, G. J., Phys. Stat. Sol. 35 (1969) 197.

[5] Cervinka, L., Kasper, J., Czech. J. Phys. B 20 (1970) 101.

[6] KILDAl, H., Technical report AFML-TR-72-277 Wright Patterson Air Force Base, Ohio, U. S. A. (1972).

[7] Kozhina, I. I., BorshchevsKir, A. S., Vesinik Leningrad Skogo Universiteta Fizika and Khimi 4 (1971) 87.

[8] Humphreys, R. G., M. Sc. Thesis, Bath University (1973).

[9] Miller, A., Holah, G. D., Clark, W. C., J. Phys. Chem. Solids 35 (1974) 685.
[10] ShaY, J. L., WeRnick, J. H., Ternary Chalcopyrite Semiconductors. Growth, electronic properties and applications (Pergamon, N. Y.) 1975.

[11] Weaire, D. L., Noolandi, J., J. Physique Colloq. 36 (1975) C 3-27.

[12] Slack, G. A., Bartram, S. F., J. Appl. Phys. 46 (1975) 89.

[13] Abrahams, S. C., Bernstein, J. L., J. Chem. Phys. 52 (1970) 5607 and J. Chem. Phys. 55 (1971) 796.

[14] Lind, M. D., Grant, R. W., J. Chem. Phys. 58 (1973) 357.

[15] Grigorovicı, R., Mănăllă, R., Acta. Crystallogr. B 24 (1968) 535.

[16] Novikova, S. I., Semiconductors and Semimetals (Ed. : Willardson \& Beer, Acad. Press) 1966, Vol, 2, p. 33.

[17] Pearson, W. B., Handbook of lattice spacings and structures of metals and alloy's (Pergamon, Oxford) 1967 Vol. 2. 